\title{
Central nervous system malformations in Mohr's syndrome
}

\author{
W REARDON*, M G HARBORD + M A HALL-CRAGGS \\ E M BRETT $\dagger$, AND M BARAITSER \\ ${ }^{*}$ Mothercare Department of Paediatric Genetics, Institute of Child Health, 30 Guilford Street, London WC1N \\ $1 E H$; and the Departments of $† N e u r o l o g y, ~ \ddagger R a d i o l o g y$, and $\S C l i n i c a l$ Genetics, Hospital for Sick Children, \\ Great Ormond Street, London WC1N 3JH.
}

SUMMARY A boy with severe developmental delay, bilateral, symmetrical hallucal duplication, and accessory alveolar frenula was found to have radiological evidence of a large arachnoid cyst compressing the cerebellum and brain stem. We review neurological abnormalities in Mohr's syndrome.

The oro-facial-digital syndrome (OFD) type II, or Mohr's syndrome, has been designated, as a separate entity from OFD type I, on the basis of autosomal recessive inheritance, bilateral hallucal reduplication, normal hair and skin, and the occasional presence of a conductive hearing loss. ${ }^{1-3}$ There has been a small number of reports of neurological features in association with Mohr's syndrome, but in general patients with OFD type II differ from type I in that intelligence is usually normal and central nervous system malformations are unusual. ${ }^{45} \mathrm{We}$ report a case with features of Mohr's syndrome in a patient who had a large posterior fossa subarachnoid cyst and occipital meningocele, which have not previously been described in this condition.

\section{Case report and investigations}

The proband, a boy, was the fourth child born to healthy, non-consanguineous, Irish parents. The pregnancy was remarkable only in that the mother noticed reduced fetal movements throughout. Spontaneous vaginal delivery took place at 38 weeks. Birth weight was $3400 \mathrm{~g}$. He was noted to be hypotonic and clinical suspicion of a meningocele was confirmed radiologically. He was a poor feeder and early in life developed marked apnoeic episodes. These were particularly prone to occur when hungry or otherwise aggravated and were often associated with cyanosis. Marked hypotonia followed these episodes but no seizures were noted. The meningocele was excised at the age of three months.

His developmental milestones were markedly



FIG 1 Accessory alveolar frenula. 
delayed and at nine months of age he had hypotonia, poor visual attention, and was unable to sit unsupported. The frequent apnoeic episodes continued. At this stage, head circumference was on the 75th centile, weight on the 25 th centile, and height on the 10th centile. He had a large, patent anterior fontanelle, mild to moderate hypertelorism, and slight ptosis of the left eyelid. Accessory alveolar frenula were noted (fig 1). The hands were free of polydactyly but the feet showed bilateral hallucal reduplication and syndactyly (fig 2). Neurological examination showed marked hypotonia, poor head control, and roving eye movements. He could follow light in the horizontal plane only and his eye movements were very jerky but there was no pendular nystagmus.

Biochemical investigations including creatine kinase, electrolytes, urate, and liver function were normal. Chromosome study confirmed a $46, X Y$ karyotype and cerebrospinal fluid protein was normal. The flash visual evoked potential (VEP) showed a low amplitude response with prolonged latency over the posterior temporal regions on both sides, suggesting some alteration of function of the primary visual cortical regions. The mid occipital flash VEP, the electroretinogram, and EEG were
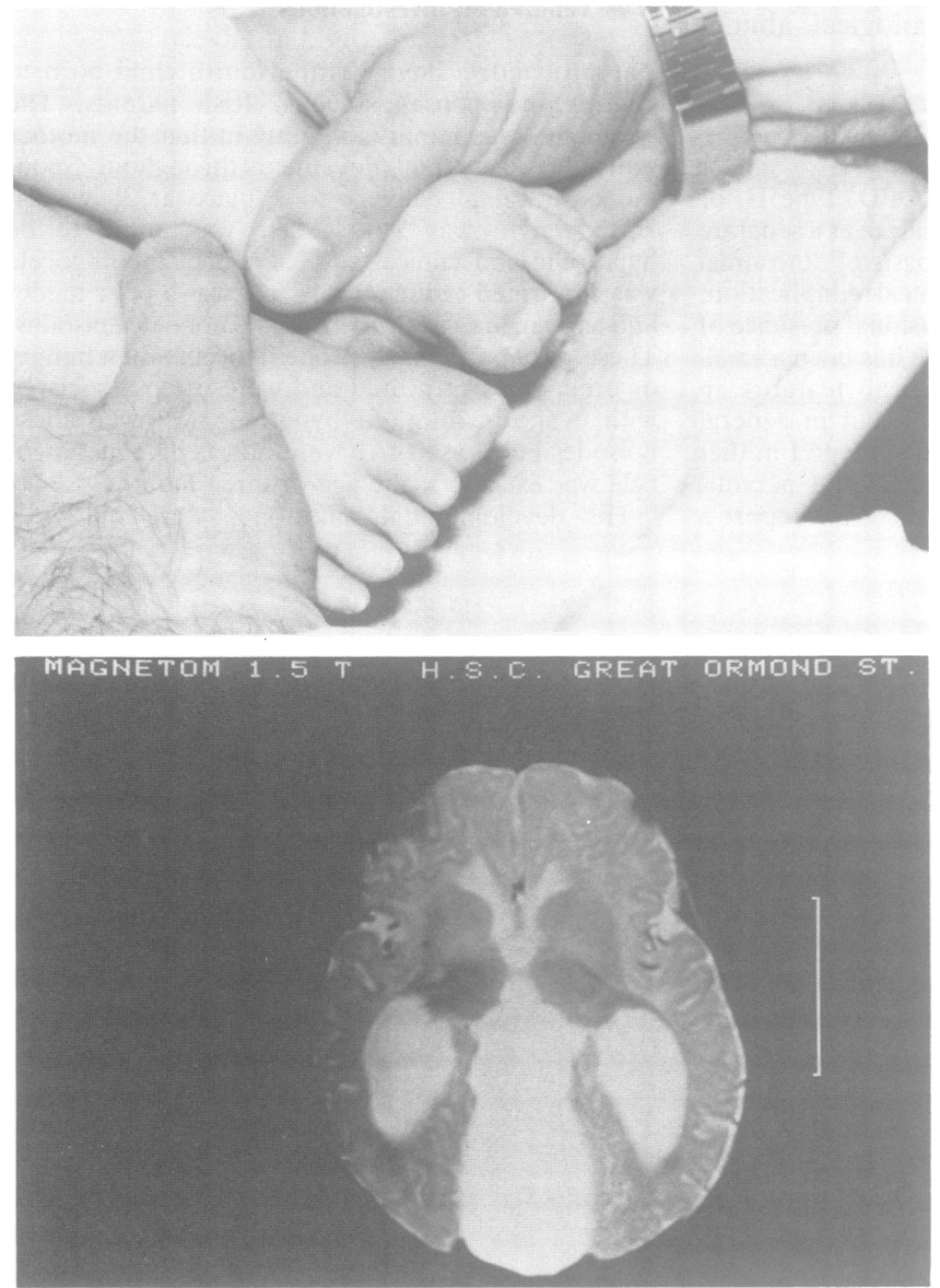

FIG 2 Bilateral hallucal reduplication and syndactyly.

FIG 3 Axial T2 weighted spin-echo $(T R=3 \mathrm{sec}$, $T E=90 \mathrm{msec}$ ). The lateral and third ventricles are dilated. The cyst is extending superiorly to flatten the quadrigeminal plate. 




FIG 4 Sagittal T1 weighted spin-echo $(T R=500 \mathrm{msec}, T E=15$ msec). A large midline arachnoid cyst is seen compressing the cerebellum and brain stem anteriorly and displacing the tentorium superiorly. There is deficient lobulation of the superior cerebellar vermis and the fourth ventricle is enlarged. normal. Brainstem auditory evoked potentials showed an absent $\mathrm{V}$ wave on both sides consistent with a structural compressive change affecting the brain stem.

A magnetic resonance scan (figs 3 and 4) was performed on a 1.5 Tesla 'Magnetom' scanner. A short TR/short TE spin-echo sequence was acquired in the sagittal plane, and a long TR/long TE spinecho sequence in the transverse plane. This showed that there was a large arachnoid cyst over the cerebellar convexities, compressing the cerebellum and brain stem anteriorly, expanding the posterior fossa, and raising the tentorium, vein of Galen, and straight sinus. It extended superiorly through the tentorial hiatus to flatten the quadrigeminal plate and impress the posterior recesses of the third ventricle. Ventricular hydrocephalus was present, affecting the lateral and third ventricles only. The whole of the superior cerebellar vermis was thin with deficient lobulation. The fourth ventricle was slightly enlarged and the roof above the fastigium was expanded posteriorly. The corpus callosum was normal. The head circumference continued to increase excessively and it eventually became necessary to shunt both the ventricles and cyst.

\section{Discussion}

Mohr's syndrome is characterised by the presence of bilateral preaxial polydactyly of the feet, a broad nasal tip, lingular tumours, conductive deafness, and the absence of skin milia. ${ }^{3}$ In addition, Mohr's syndrome is inherited as an autosomal recessive trait whereas the $\mathrm{X}$ linked dominant inheritance in OFD type I limits the clinical manifestations to females only. ${ }^{6}$

The first report of neurological features in Mohr's syndrome came from Haumont and Pelc ${ }^{4}$ (table 1). The radiological features described in both sibs were those of Dandy-Walker malformations. Facial dysmorphism included midface hypoplasia, hypertelorism, antimongoloid slant, broad nasal root, bifid nasal tip, cleft palate, microglossia, lobulated tongue, thick frenulum, and low set ears. Hand abnormalities were polysyndactyly of an unspecified nature and brachydactyly with proximally implanted thumbs. The feet, in both cases, showed bilateral reduplication of the hallux. Hypotonia and apnoeic episodes were noted in both patients and one had convulsions.

The other report of neurological features in Mohr's syndrome is that of Gustavson et al. ${ }^{5}$ An air encephalogram in case 2 showed fourth ventricular dilatation, a finding which may be consistent with the Dandy-Walker malformation. Case 1 did not have any neuroradiological or neuropathological investigations. Lingular tumours on either side of the tongue and epicanthic folds were the orofacial features reported in case 2 but none was recorded in case 1 . Case 1 had no hand malformation, while case 2 had postaxial polydactyly of the hands bilaterally. Malformations of the feet in case 1 consisted of a reduplication of the halluces bilaterally and, whereas case 2 shared this feature bilaterally, there was also unilateral postaxial polydactyly in the right foot. Both patients showed marked hyperpnoea. 
TABLE 1 Clinical anomalies.

\begin{tabular}{|c|c|c|c|c|c|c|}
\hline & $O F D I$ & $O F D I I$ & $\begin{array}{l}\text { Joubert's } \\
\text { syndrome }\end{array}$ & $\begin{array}{l}\text { Haumont } \\
\text { and Pelc }\end{array}$ & $\begin{array}{l}\text { Gustavson } \\
\text { et } a 5^{5}\end{array}$ & $\begin{array}{l}\text { Present } \\
\text { case }\end{array}$ \\
\hline \multicolumn{7}{|l|}{ Orofacial } \\
\hline Hypertelorism & + & + & - & + & $?$ & + \\
\hline Broad nose & + & + & - & + & $?$ & - \\
\hline Lingular tumours & + & + & - & - & + & - \\
\hline Accessory frenula & + & + & - & - & $?$ & + \\
\hline Thickened normal frenula & + & + & - & + & $?$ & - \\
\hline Midline clefting & + & + & - & + & - & - \\
\hline Skin milia & + & - & - & $?$ & - & - \\
\hline \multirow[t]{2}{*}{ Alopecia } & + & - & - & ? & - & - \\
\hline & & & & Case & Case & \\
\hline Hand/foot & & & & 12 & 12 & \\
\hline Little finger reduplication & + & + & + & $? \quad-$ & $?+$ & - \\
\hline Hallux reduplication & Unilateral only & Bilateral & - & Bilateral & Bilateral & Bilateral \\
\hline Little toe reduplication & - & + & - & $-\quad-$ & $?+$ & - \\
\hline \multicolumn{7}{|l|}{ Neurological } \\
\hline Jerky eye movement & - & - & + & $?$ & $?$ & + \\
\hline Abnormal breathing pattern & - & - & + & ++ & ++ & + \\
\hline Mental retardation & + & $?$ & + & $? \quad ?$ & $?+$ & + \\
\hline Conductive deafness & - & + & - & $? \quad ?$ & $? \quad ?$ & - \\
\hline Hypotonia & + & $?$ & + & ++ & $?+$ & + \\
\hline \multicolumn{7}{|l|}{ Sex } \\
\hline Sex distribution & Females & Male and female & Male and female & Females & Females & Male \\
\hline
\end{tabular}

TABLE 2 Neuroradiological features.

\begin{tabular}{llll}
\hline Joubert's syndrome & Haumont and Pelc & Gustavson et at & Present case \\
\hline $\begin{array}{l}\text { Abnormally high fourth ventricle. } \\
\begin{array}{l}\text { Deficient superior cerebellar vermis. } \\
\text { Midline vermis cleft }\end{array}\end{array}$ & $\begin{array}{c}\text { Dandy-Walker } \\
\text { malformation }\end{array}$ & $\begin{array}{c}\text { Dilated fourth ventricle on } \\
\text { air encephalography }\end{array}$ & $\begin{array}{l}\text { Subarachnoid cyst above fourth ventricle. } \\
\text { Hypoplasia of superior cerebellar vermis. } \\
\text { Hydrocephalus }\end{array}$ \\
\hline
\end{tabular}

There is no doubt that CNS anomalies in OFD type I are frequent. Among those seen most commonly are agenesis of the corpus callosum and the presence of ependymal cysts. ${ }^{8}$ Other abnormalities described include an occipital encephalocele, the Dandy-Walker malformation, and hypoplasia of the cerebellar hemisphere and vermis, the latter being the structural features of Joubert's syndrome. One of the cardinal differences between Mohr's syndrome and OFD type $I$ is the bilateral preaxial polydactyly of the feet in the former, whereas the hand polydactyly in Mohr's syndrome may be preor postaxial. ${ }^{3}$

The case we describe has features of Mohr's syndrome: bilateral reduplication of the halluces with hypertelorism and accessory alveolar frenula. The main differential diagnosis is from Joubert's syndrome. This appears to be a separate clinical entity, characterised by episodic hyperpnoea, jerky eye movements, and developmental delay. ${ }^{79}$ Neuropathological features noted at brain necropsy in Joubert's syndrome ${ }^{10}$ are cerebellar vermis aplasia, heterotopia of cerebellar nuclei, anomalies at the cervicomedullary junction, an absence of the pyramidal tract decussation, and abnormalities of solitary and gracile nuclei.

Neuroradiological features of Joubert's syndrome are an abnormal fourth ventricle, extending upwards much higher than normal, a deficient superior cerebellar vermis, and midline vermis cleft (table 2 ). Although our patient had jerky eye movements, he had no hyperpnoea and the neuroradiological findings were not consistent with Joubert's syndrome. Indeed, the MRI scan shows an intact fourth ventricle with a large subarachnoid cyst, compressing the cerebellum (fig 4).

We present this case of Mohr's syndrome to suggest that the range of CNS malformations in this condition is larger than previously reported. Furthermore, structural neurological abnormalities may be common to both types of OFD syndrome. It remains uncertain whether the condition described by Haumont and Pelc, ${ }^{4}$ Gustavson et al, ${ }^{5}$ and the $\stackrel{\Phi}{\varrho}$ patient in this report share a distinct syndrome 
characterised by the presence of mental retardation, periods of apnoea, preaxial polydactyly, lingular tumours/accessory frenula, and neuroradiological abnormalities in the vicinity of the fourth ventricle, but which differs from the characteristic picture seen in Joubert's syndrome.

\section{References}

${ }^{1}$ Mohr O. A hereditary sublethal syndrome in man. Avhandlinger Utgitt av det Norske Videnskaps-Akademi i Oslo. 1. Mat-Naturv klasse 1941;14:3-17.

2 Rimoin DL, Edgerton MT. Genetic and clinical heterogeneity in the oro-facial-digital syndromes. $J$ Pediatr 1967;71:94-102.

3 Temtamy SA, McKusick VA. The genetics of hand malformations. Birth Defects 1978;XIV(No 3).

4 Haumont D, Pelc S. The Mohr syndrome-are there two variants? Clin Genet 1983;24:41-6.

${ }^{5}$ Gustavson KH, Kreuger A, Peterson PO. Syndrome characterised by lingual malformation, polydactyly, tachypnea and psychomotor retardation (Mohr syndrome). Clin Genet 1971;2: 261-6.
${ }^{6}$ McKusick VA. Mendelian inheritance in man. 8th ed. Baltimore: Johns Hopkins University Press, 1988.

7 Joubert M, Eisenring JJ, Robb JP, Andermann F. Familial agenesis of the cerebellar vermis. A syndrome of episodic hyperpnea, abnormal eye movements, ataxia and mental retardation. Neurology (Minneap) 1969;19:813-25.

8 Towfighi J, Berlin CM, Ladda RL, Frauenhoffer EE, Lehman RAW. Neuropathology of oro-facial-digital syndromes. Arch Pathol Lab Med 1985;109:642-6.

${ }^{9}$ King MD, Dudgeon J, Stephenson JBP. Joubert's syndrome with retinal dysplasia: neonatal tachypnoea as the clue to a genetic brain-eye malformation. Arch Dis Child 1984;59: 709-18.

${ }^{10}$ Friede RL, Bolthauser E. Uncommon syndromes of cerebellar vermis aplasia. I. Joubert syndrome. Dev Med Child Neurol 1978;20:758-63.

Correspondence to Dr W Reardon, Mothercare Department of Paediatric Genetics, Institute of Child Health, 30 Guilford Street, London WC1N $1 \mathrm{EH}$. 